\title{
Disentangling the cause of a catastrophic population decline in a large marine mammal
}

\author{
Alastair M. M. Baylis, ${ }^{1,2,3,9}$ Rachael A. Orben, ${ }^{4,5}$ John P. Y. Arnould,${ }^{1}$ Fredrik Christiansen,,${ }^{1,6}$ \\ Graeme C. Hays, ${ }^{1,7}$ and Iain J. Staniland ${ }^{8}$ \\ ${ }^{1}$ Centre for Integrative Ecology, School of Life and Environmental Sciences, Deakin University, Warrnambool, \\ Victoria 3280 Australia \\ ${ }^{2}$ South Atlantic Environmental Research Institute, Stanley FIQQ1ZZ Falkland Islands \\ ${ }^{3}$ Falklands Conservation, Ross Road, Stanley FIQQ1ZZ Falkland Islands \\ ${ }^{4}$ Department of Ocean Sciences, University of California, Long Marine Lab, Santa Cruz, California 95060 USA \\ ${ }^{5}$ Department of Fisheries and Wildlife, Oregon State University, Hatfield Marine Science Center, Newport, Oregon 97365 USA \\ ${ }^{6}$ Cetacean Research Unit, School of Veterinary and Life Sciences, Murdoch University, Murdoch, \\ Western Australia 6150 Australia \\ ${ }^{7}$ Department of Biosciences, Swansea University, Singleton Park, Swansea SA28PP United Kingdom \\ ${ }^{8}$ British Antarctic Survey NERC, High Cross, Madingley Road, Cambridge CB3 OET United Kingdom
}

Abstract. Considerable uncertainties often surround the causes of long-term changes in population abundance. One striking example is the precipitous decline of southern sea lions (SSL; Otaria flavescens) at the Falkland Islands, from 80555 pups in the mid 1930s to just 5506 pups in 1965. Despite an increase in SSL abundance over the past two decades, the population has not recovered, with the number of pups born in 2014 (minimum 4443 pups) less than $6 \%$ of the 1930s estimate. The order-of-magnitude decline is primarily attributed to commercial sealing in Argentina. Here, we test this established paradigm and alternative hypotheses by assessing (1) commercial sealing at the Falkland Islands, (2) winter migration of SSL from the Falkland Islands to Argentina, (3) whether the number of SSL in Argentina could have sustained the reported level of exploitation, and (4) environmental change. The most parsimonious hypothesis explaining the SSL population decline was environmental change. Specifically, analysis of 160 years of winter sea surface temperatures revealed marked changes, including a period of warming between 1930 and 1950 that was consistent with the period of SSL decline. Sea surface temperature changes likely influenced the distribution or availability of SSL prey and impacted its population dynamics. We suggest that historical harvesting may not always be the "smoking gun" as is often purported. Rather, our conclusions support the growing evidence for bottom-up forcing on the abundance of species at lower trophic levels (e.g., plankton and fish) and resulting impacts on higher trophic levels across a broad range of ecosystems.

Key words: bottom-up forcing; historical baselines; killer whales; megafaunal collapse; ocean climate; Orcinus orca; pinniped; South Atlantic; top-down control.

\section{INTRODUCTION}

Diagnosing the cause of long-term changes in the abundance of plants and animals is a basic tenet of ecology and is at the heart of many conservation efforts (Caughley and Gunn 1996). For large vertebrates, harvesting and habitat loss have driven global declines in a broad range of marine and terrestrial species (Myers and Worm 2003, Lotze and Worm 2009), leading to the current view that a major anthropogenically induced global extinction event is underway (Barnosky et al. 2011). In addition to harvesting and habitat loss, other processes are responsible for long-term changes in abundance, including shifts in predator-prey interac-

Manuscript received 15 October 2014; revised 19 February 2015; accepted 24 February 2015; final version received 19 March 2015. Corresponding Editor: D. C. Speirs.

${ }^{9}$ E-mail: al_baylis@yahoo.com.au tions and abrupt, persistent climate changes (Chavez et al. 2003, Dirzo et al. 2014). However, diagnosis of these factors is typically hindered by fundamental inadequacies in available data and uncertainties over the links between anthropogenic factors and physical and biological processes, which can be subtle, complex, and act in synergy (Croxall 1992, Jenouvrier et al. 2005, Ainley et al. 2007, Ainley and Hyrenbach 2010). For instance, the decline of Steller sea lions (Eumetopias jubatus) between the late 1970s and 1990s in the North Pacific Ocean and southern Bering Sea could be a consequence of physical oceanographic changes associated with a climate regime shift in 1976-1977 (Anderson and Piatt 1999, Hare and Mantua 2000, Trites et al. 2007). However, there is also a compelling argument that increased predation by killer whales (Orcinas orca) was responsible for this decline; the consequence of a reduction in great whale biomass due to industrial whaling (the sequential 
megafaunal collapse hypothesis; Springer et al. 2003, Estes et al. 2009). Hence, considerable uncertainties typically accompany established paradigms that synthesize and shape our understanding of population declines, making it important to revisit and reevaluate these paradigms as new information becomes available and existing data sets are improved.

Here, we focus on southern sea lions (SSL; Otaria flavescens), which have suffered a well-known, yet poorly understood population decline at the Falkland Islands (South Atlantic). Between the 1930s and 1965, SSL declined by $95 \%$ at the Falkland Islands, from an estimated 371500 animals to $<30000$ (Hamilton 1939, Strange 1979). Seminal SSL studies propose several hypotheses to explain the decline, including commercial sealing at the Falkland Islands (most authors accept 42741 SSL were killed between 1935 and 1966, but this estimate has not been critically analyzed) and environmental change (Strange 1979, Thompson et al. 2005). However, the prevailing hypothesis is commercial sealing in Argentina (Thompson et al. 2005, Branch and Williams 2006). This hypothesis is compelling, in part because the mechanistic explanation is simple and because 20th century sealing is synonymous with catastrophic pinniped population declines (Caughley and Gunn 1996, Gerber and Hilborn 2001). It is also convenient. SSL colonies in Argentina are thought to have been unable to sustain the reported level of exploitation because (1) a previous study estimates 349000 SSL for the 1938 Argentinean population, and (2) a discrepancy exists between the number of SSL killed at select colonies in Argentina and colony size (Thompson et al. 2005, Branch and Williams 2006). Hence, by merging the total number of SSL estimated at the Falkland Islands with those estimated in Argentina (or counts at select colonies), it is possible to account for the 493438 SSL killed during commercial sealing operations in Argentina between 1930 and 1960 (Thompson et al. 2005, Branch and Williams 2006).

However, implicit in the prevailing hypothesis is the existence of an annual austral winter migration of SSL from the Falkland Islands to Argentina. Migration from the Falkland Islands was first proposed in the 1930s because the number of SSL at one breeding colony (Cape Dolphin) steadily declined as winter approached and a large group of SSL were observed swimming in the same direction (Hamilton 1939). Based on these observations, the International Union for Conservation of Nature (IUCN) concludes that SSL abandon the Falkland Islands during winter (Campagna 2014). Yet, despite the anecdotal IUCN assessment, migration has not been documented. Indeed, only one SSL at the Falkland Islands has been successfully tracked at sea, and this occurred during summer (Thompson et al. 1998). Consequently, striking uncertainties accompany the prevailing hypothesis and the current IUCN conservation assessment.
To redress these uncertainties, we assess the current population size of SSL at the Falkland Islands and blend these estimates with historical census data. Next, by considering both potential top-down down control (commercial sealing) as well as bottom-up control (environmental change impacting prey abundance), we provide a holistic appraisal of the likely drivers of the SSL decline between the 1930s and 1965. In this way, our work sheds new light on the factors that may have contributed to long-term changes in SSL abundance. While our study is concerned with SSL, many sea lion populations are under threat or have yet to recover from exploitation (Costa et al. 2004). Hence, results from this study have a wider application in assessing and understanding causality.

\section{Materials and Methods}

The life-history characteristics of SSL include annual, synchronous breeding. Adult males typically establish territories in December (Hamilton 1934). Pups are born from mid-December to early February (the austral summer), after which adult females alternate between foraging at sea and attending their pup ashore (RietSapriza et al. 2013). Pups are weaned at $8-10$ months old, although it is not unusual for females to continue to care for a yearling while they are nursing a new pup (Hamilton 1939). SSL breeding at other sites are not considered migratory, although large seasonal movements during the nonbreeding season (March-November) occur (Giardino et al. 2014).

\section{Current population size and trends}

We undertook the fifth archipelago-wide census of SSL between 16 January and 12 February 2014 (earlier censuses were undertaken in the 1930s, 1965, 1995, and 2003). All known SSL breeding colonies were visited via a charter boat (each site was visited only once; Fig. 1). The timing of the 2014 census (mid-January, post peak pupping) was consistent with the recommended census period first established in the 1930s (Hamilton 1934, 1939) and subsequently used in the 1995 and 2003 censuses (Thompson et al. 2005). It is generally accepted that counts of pups provide a better index of population size and trends when compared to counts of adults (Trites and Larkin 1996). Hence, SSL pups were counted by two observers either (1) ashore, from one or more vantage points overlooking the breeding colony, (2) direct counted from the charter boat (or zodiac) but from several vantage points along the shoreline, or (3) counted from photographs taken from the top of the boat mast $(15 \mathrm{~m})$, when the boat was close to shore (typically $<10 \mathrm{~m}$ ). Counts were complete because breeding colonies were typically small ( $64 \pm 58$ pups; mean $\pm \mathrm{SD}$ ), enabling each count to be repeated until the total number of pups was obtained. Therefore, the number of pups counted represents the minimum number of pups born. Sources of count error are detailed in the supplementary material (Appendix A: 


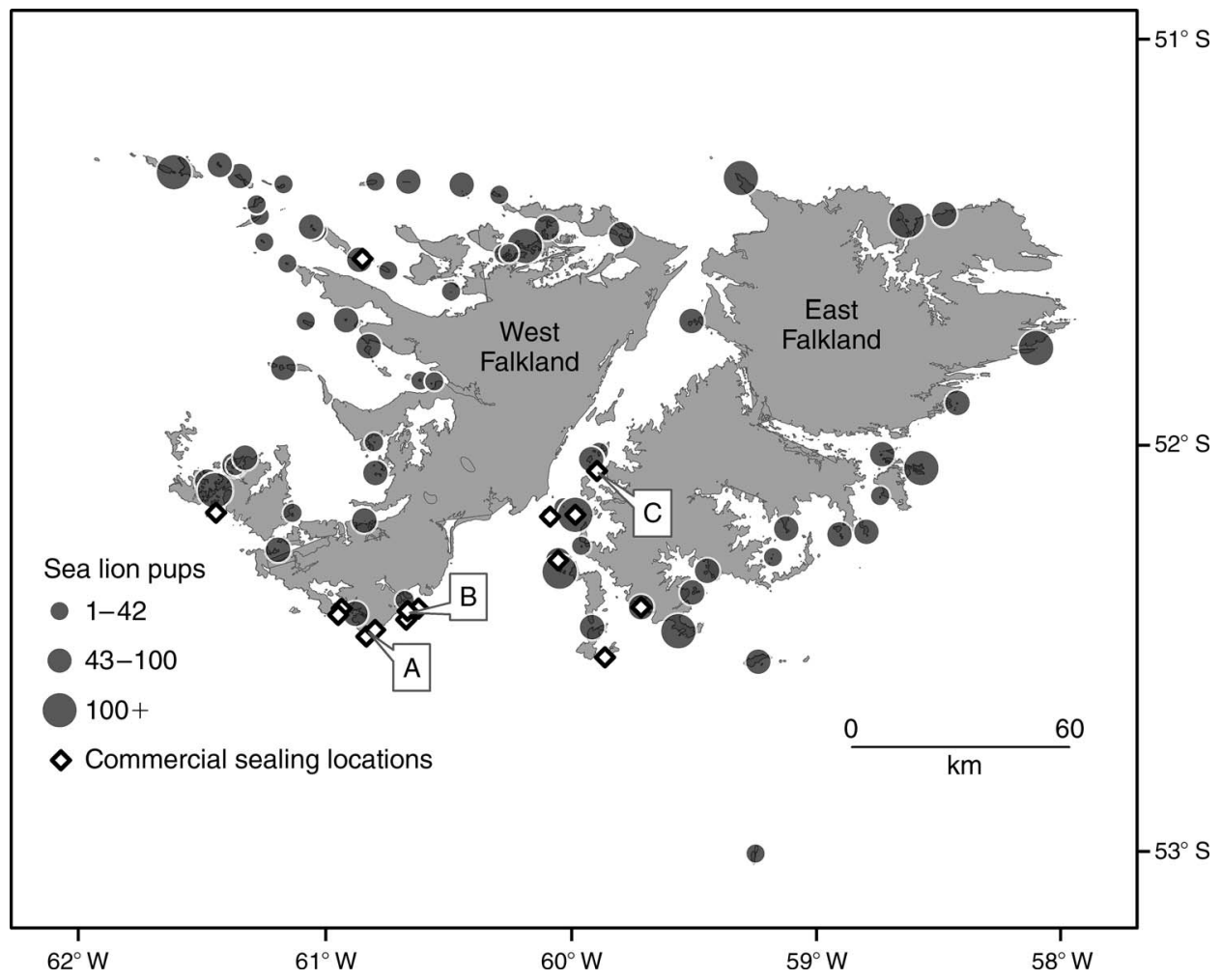

FIG. 1. Location and size of southern sea lion (Otaria flavescens) breeding colonies at the Falkland Islands, South Atlantic. Also presented are commercial sealing locations (1928-1965), revealing that sealing was spatially restricted. Between 1935 and 1965 (the period of decline), $87 \%$ of southern sea lions were killed at the three locations highlighted: Cape Meredith (A; 28\%), Arch Islands group (B; 24\%), and Sandbar Island (C; 35\%).

section A1). In the 1930s, count methods involved spook counts; clearing a breeding beach of adults and herding pups into groups where they were direct counted (Hamilton 1939). However, at nine breeding sites out of the 64 counted in the 1930s, the number of pups were "estimated" and not counted (3\% of pups; see Appendix A: Table A1). The 1930s census was conducted between 1931 and 1937, with the majority (99\%) of pups counted between 1934 and 1937 (1934, 19\%, 15678 pups; 1935, 64\%, 51686 pups; 1936, 11\%, 9001 pups; 1937, 4\%, 3393 pups; Hamilton 1939). The 1995 and 2003 censuses were also direct counts, whereas the 1965 census was an aerial survey (Strange 1979). An aerial survey was also undertaken in 1990, however, not all breeding colonies were counted (Thompson et al. 2005). This partial count (total 599 pups) was not included in our analysis.

\section{Hypotheses}

Decline was the result of commercial sealing at the Falkland Islands.--To determine (1) sealing locations, (2) numbers killed annually, and (3) sex, we examined all available documents relating to sealing between the early 1900s and the end of sealing in 1966 (documents housed at the Jane Cameron National Archives, Stanley, Falkland Islands). To test the hypothesis that the population decline was the result of commercial sealing at the Falkland Islands, we constructed a simple femaleage-based population matrix model using sea lion census data from the 1930s (Hamilton 1939). The starting population was 40277 female pups (half of the 80555 pups counted in the 1930s census, assuming an equal sex ratio) and 73024 juvenile female SSL (Hamilton 1939). By inference, the number of adult females was at least 80555 (Hamilton 1939).

The model was parameterized using survival and fecundity estimates for Steller sea lions (Eumetopias jubatus), because these estimates are not available for SSL (York 1994, Thompson et al. 2005). Female SSL start to recruit into the breeding population at age 4 (Hamilton 1939) and are assumed to be fully recruited by age 7 (Thompson et al. 2005). Therefore, age-specific fecundity was $f_{4}=0.33 \times F_{\mathrm{a}}, f_{5}=0.85 \times F_{\mathrm{a}}, f_{6}=0.90 \times$ $F_{\mathrm{a}}, f_{7}=F_{\mathrm{a}}$; subscripted numbers refer to age of SSL, $F_{\mathrm{a}}$ refers to adult fecundity. Age-specific survival was $S_{\text {pup }}$ $=0.60, S_{\mathrm{j}}=0.86, S_{\mathrm{a}}=0.88$, where $S_{\mathrm{j}}$ is juvenile survival and $S_{\mathrm{a}}$ is adult survival (see Appendix B: Fig. B1). The stable age distribution was computed using the $\mathrm{R}$ package popbio (Stubben and Milligan 2007) and a stationary population size $(\lambda=1)$ was obtained by gradually modifying fecundity $\left(F_{\mathrm{a}}\right)$ until zero growth was achieved (at $F_{\mathrm{a}}=0.352$ ). Using the initial population size (193 856), distributed across the different age classes 
TABLE 1. The number and sex of southern sea lions (Otaria flavescens) killed during commercial sealing operations at the Falkland Islands between 1928 and 1966.

\begin{tabular}{lclc}
\hline \hline Year & $\begin{array}{c}\text { No. of sea lions } \\
\text { killed (range) } \dagger\end{array}$ & Months of operation & Adult males $\dagger$ \\
\hline 1928 & $3139-3739$ & June-February (1929) & $100 \%$ \\
1929 & 2065 & May-July & $100 \%$ \\
1930 & $4941-7017$ & May-October & $71-80 \%$ \\
1931 & $2819-7819$ & Unknown & $100 \%$ \\
1933 & 7487 & July-September & $100 \%$ \\
1935 & $9129-9255$ & May-October & $100 \%$ \\
1936 & $9081-9145$ & May-September & $100 \%$ \\
1937 & 7285 & June-October & $100 \%$ \\
1939 & 2917 & June-August & $100 \%$ \\
1950 & 1323 & August-January (1951) & $100 \%$ \\
1951 & $1889-2187$ & July-November & $100 \%$ \\
1964 & 147 & June & $100 \%$ \\
1966 & 337 & August & $100 \%$ \\
Total (maximum) & 60723 & & 59300 \\
\hline
\end{tabular}

Notes: Data compiled from reference folders NAT/SEA/3-NAT/SEA/5 at the Jane Cameron National Archives, Falkland Islands. Sex is denoted as the percentage of the yearly harvest. No report was found for 1931, but the number of sea lions killed is reported in Hamilton (1939) and in letters to the Falkland Islands Government. For 1933, a sealing report exists, but Hamilton (1939) and Strange (1979) report no sealing between 1931 and 1935. A request was granted to kill all age/ sex classes of sea lions on Blind Island (East Falkland) in 1933. However, the sealing report stipulates that Blind Island was not visited. In 1964, a license to take 1500 adult male sea lions was granted. No report is available for 1964, but correspondence indicates 147 sea lions killed in June 1964. In 1965, a license to take 1500 adult male sea was lions granted. No report is available, but correspondence indicates 337 male sea lions 2-4 years old were killed in August 1966. Because it can be difficult to distinguish sex of young (i.e., 2-yr old) sea lions, it is possible that females were also killed.

$\uparrow 1930$ was the only year in which a harvest of adult females and pups was reported: 1423 sea lions (20-29\% of total harvest). Dickinson (2007) miss-reports, 1523 adult females and pups.

in accordance with the computed stable age distribution, we then modeled the effect of commercial sealing at the Falkland Islands. For the simulation, we assumed that all harvested animals were females, and that the mortality from sealing was zero for ages 0 and 1 and proportional to the size of the age class for older age classes (Thompson et al. 2005, Branch and Williams 2006). In contrast to previous studies (Thompson et al. 2005, Branch and Williams 2006), we did not assume an equal number of SSL were killed annually between 1935 and 1965, but used our revised estimates of SSL killed over this period (Table 1). We compared the predicted population size from our simulated model to actual SSL census data from 1965.

Commercial sealing in Argentina caused Falkland Islands decline due to winter migration of SSL from Falkland Islands to Argentina.-In May 2011 and 2012, we deployed 10 Platform Transmitter Terminal (PTT) tags of ARGOS location quality (Kiwisat 202; Sirtrack, Havelock North, New Zealand) on subadult SSL at two breeding colonies to determine whether they migrate over winter (Fig 1, Table 2). Based on size and pelage (including lack of a developed mane), we estimated these animals were between 2.5 and $4 \mathrm{yr}$ old. We selected subadult SSL because (1) sealing in the Falkland Islands mainly targeted adult males during the winter (this study) and, therefore, historical data implies that adult males do not migrate at this time of year; and (2) adult female SSL have a long lactation period ( $\sim 11$ months), during which time they are obligate central place foragers and therefore unlikely to undertake a migration in winter to Argentina (Rodríguez et al. 2013). In contrast, subadult SSL are free from central place foraging constraints (Hückstädt et al. 2014) and are therefore more likely to disperse from the Falkland Islands.

SSL were chemically restrained by a remote injection of tiletamine-zolazepam (Zoletil, Virbac, France; $3 \mathrm{mg} /$ $\mathrm{kg}$ of estimated weight), administered using $1.5 \mathrm{cc}$ Pnue Darts and $\mathrm{C}_{2}$ powered tranquilizer gun (Dan-Inject JM Standard, Austin, Texas, USA) (Baylis et al. 2015). PTT tags were glued to the back of SSL using a two-part epoxy (five-minute epoxy; Devcon, Danvers, Massachusetts, USA) and programmed to transmit every $45 \mathrm{~s}$. In 2011, PTT tags were programmed to transmit continuously, while in 2012 PTT tags had a 12-h on/12-h offduty cycle interval to preserve battery life. We defined a foraging trip as an extended excursion $>5 \mathrm{~km}$ from land and $>2 \mathrm{~d}$ in duration. Least-squares-location-processed ARGOS data were filtered using a continuous-time correlated random walk model that incorporates ARGOS location error for each of the six location classes (3, 2, 1, 0, A, B; R package crawl; Johnson et al. 2008). The most likely track produced by the model was used to interpolate hourly locations (including periods when the PTT tag was off). These locations were used to calculate foraging trip duration and the maximum distance from the Falkland Islands. 
TABLE 2. Foraging trip characteristics of 10 juvenile southern sea lions tracked during winter at the Falkland Islands.

\begin{tabular}{|c|c|c|c|c|c|c|c|c|c|}
\hline \multirow{2}{*}{$\begin{array}{l}\text { Sea lion ID and } \\
\text { deployment year }\end{array}$} & \multirow{2}{*}{$\begin{array}{l}\text { Deployment } \\
\text { date }\end{array}$} & \multirow[b]{2}{*}{ Location } & \multirow[b]{2}{*}{ Sex } & \multirow{2}{*}{$\begin{array}{l}\text { Standard } \\
\text { total body } \\
\text { length }(\mathrm{cm})\end{array}$} & \multirow{2}{*}{$\begin{array}{l}\text { No. of } \\
\text { foraging } \\
\text { trips }\end{array}$} & \multicolumn{2}{|c|}{$\begin{array}{c}\text { Maximum } \\
\text { distance per trip }(\mathrm{km})\end{array}$} & \multirow{2}{*}{$\begin{array}{l}\text { Trip } \\
\text { duration } \\
\text { (d) }\end{array}$} & \multirow{2}{*}{$\begin{array}{c}\text { Total } \\
\text { deployment } \\
\text { duration (d) }\end{array}$} \\
\hline & & & & & & Mean & Range & & \\
\hline \multicolumn{10}{|l|}{2011} \\
\hline 1543 & 10 May & $\mathrm{CD}$ & M & 154 & 7 & $64(13)$ & $49-81$ & $4(1)$ & 46 \\
\hline 1555 & 8 May & $\mathrm{PH}$ & F & 142 & 3 & $21(11)$ & $12-33$ & $3(1)$ & 206 \\
\hline 2162 & 9 May & $\mathrm{CD}$ & M & 184 & 13 & $65(23)$ & $53-140$ & $3(1)$ & 205 \\
\hline 6074 & 10 May & $\mathrm{CD}$ & $\mathrm{M}$ & 188 & 18 & $123(61)$ & $69-268$ & $5(2)$ & 193 \\
\hline 30205 & 10 May & $\mathrm{CD}$ & $\mathrm{F}$ & 145 & 16 & $63(9)$ & $48-78$ & $2(1)$ & 98 \\
\hline 103751 & 10 May & CD & $\mathrm{M}$ & 166 & 5 & $141(48)$ & $96-211$ & $6(1)$ & 54 \\
\hline \multicolumn{10}{|l|}{2012} \\
\hline 68025 & 2 May & $\mathrm{CD}$ & M & 175 & 7 & 83 (13) & $57-94$ & $5(1)$ & 87 \\
\hline 68034 & 2 May & $\mathrm{CD}$ & $\mathrm{F}$ & 138 & 3 & 67 (9) & $57-76$ & $5(3)$ & 24 \\
\hline 68048 & 2 May & CD & M & 168 & 0 & & & & 30 \\
\hline 67957 & 4 May & PH & $\mathrm{F}$ & 167 & 0 & & & & 56 \\
\hline Total & & & & 163 (17) & 72 & $84(47)$ & $12-268$ & $4(1)$ & $100(74)$ \\
\hline
\end{tabular}

Notes: Deployment locations (Falkland Islands) were Cape Dolphin (CD) and Port Harriet (PH). Values for total body length, mean maximum distance per trip, trip duration, and total deployment duration are given with SD in parentheses. A foraging trip was defined as $>5 \mathrm{~km}$ in distance and $>2 \mathrm{~d}$ in duration. Cells left blank indicate no data available.

SSL colonies in Argentina were unable to sustain the reported level of exploitation.-We also reviewed census and commercial sealing data from Argentina (Godoy 1963) to explore the suggestion that SSL colonies in Argentina were unable to sustain the reported level of exploitation (underpinning the notion of migration; Thompson et al. 2005, Branch and Williams 2006). In 1938, a total of 671500 SSL were estimated in Argentina (excluding Tierra del Fuego; Table 3; Appendix B: Table B1). This estimate should be viewed as a relative index of population size given that count methods (and potential error) are not described (Crespo and Padraza 1991). In the absence of age or sex data, we pooled counts across provinces (we could not account for spatial or temporal population variability) and used the same age-specific survival and fecundity values as the Falkland Islands population model, and hence the same stable age distribution. As for the Falkland Islands population, we assumed a 50:50 sex ratio. We modified fecundity to create a stationary-age distribution (again using $F_{\mathrm{a}}=0.352$ ). The starting population was 335750 female SSL, including 58532 pups (see Appendix B: Fig. $\mathrm{B} 1)$.

Between 1936 and 1960, 460527 SSL skins were produced (Godoy 1963; Table 4). We modeled the effect of commercial sealing between 1936 and 1960 on the

TABLE 3. The number of southern sea lions in Argentina (by province) in 1938 and 1950 and number killed during commercial sealing operations between 1920 and 1960 .

\begin{tabular}{|c|c|c|c|c|c|c|}
\hline Province & $\begin{array}{c}\text { Estimated } \\
\text { population } 1938\end{array}$ & $\begin{array}{c}\text { Colonies } \\
\text { counted } 1938\end{array}$ & $\begin{array}{c}\text { Years } \\
\text { harvested }\end{array}$ & $\begin{array}{c}\text { Minimum } \\
\text { number killed }\end{array}$ & $\begin{array}{c}\text { Estimated } \\
\text { population } 1950\end{array}$ & $\begin{array}{c}\text { Colonies } \\
\text { counted } 1950\end{array}$ \\
\hline Buenos Aires & 40000 & 2 & $1937-1945$ & 34338 & 275 & 3 \\
\hline Rio Negro & 18000 & 1 & 1938-1943 & 6481 & 5500 & 2 \\
\hline Chubut & 229500 & 6 & 1920-1960 & 203660 & 50130 & 20 \\
\hline Punta Buenos Aires & 15000 & & $1920-1960$ & & 3000 & \\
\hline Punta Norte & 40000 & & $1920-1960$ & & 3000 & \\
\hline Punta Delgada & 52500 & & $1920-1960$ & & 2400 & \\
\hline Punta Ninfas & 12000 & & 1920-1960 & 203259 & 3200 & \\
\hline Isla Escondida & 5000 & & 1931 & 336 & 2500 & \\
\hline Isla Rasa & 105000 & & & & 7000 & \\
\hline Santa Cruz & 384000 & 5 & 1927-1949 & 188170 & 48690 & 20 \\
\hline Tierra del Fuego & unknown & 0 & 1937-1949 & 148947 & 39900 & 27 \\
\hline Total & 671500 & 14 & & 432649 & 144495 & 71 \\
\hline
\end{tabular}

Notes: Also presented is a breakdown of colonies in Chubut Province, where the discrepancy in the number of southern sea lions killed at Punta Buenos Aires, Punta Norte, Punta Delgada, and Punta Ninfas is used to support the notion of southern sea lion migration from the Falkland Islands to Argentina (see also Fig. 4; source: Godoy 1963). The number of sea lions killed (by province) does not equal the 493438 skins and hides produced between 1931 and 1960 (Table 4; data from the same report). Disparity in the number of colonies between 1930 and 1950 reflects expansion in the number of colonies over this period (the exception being Tierra del Fuego, where no count data was available in the 1930s). Total number of sea lions killed in Chubut includes 65 southern sea lions killed at Punta Loberia in 1938-1940; no count data for this site in 1938. The estimated 1950 population for Buenos Aires Province was based on counts undertaken 1946-1960. Commercial sealing appears to have occurred at Isla Rasa in 1918 and 1928, but the original document has a question mark. This could either indicate numbers taken are unknown, or that numbers from this site have been integrated elsewhere. 
female component of the hypothetical Argentinean SSL population by assuming (1) mortality from sealing was zero for ages 0 to 1 and proportional to the size of the age class for older age classes (Branch and Williams 2006), (2) an equal number of male and female SSL were killed each year, (3) an equal number of SSL were killed annually between 1936 and 1960 (see Appendix B: Table B2), equating to 460527 SSL killed in total (Thompson et al. 2005), and (4) the estimated number of SSL in 1938 was equal to the number in 1936 (no population data exists for 1936). We emphasize that our aim with the limited data available was to test whether it was feasible for a hypothetical population to sustain the reported level of exploitation, rather than an attempt to recreate past events.

Environmental change.-Ocean productivity around the Falkland Islands is dominated by the cold-water Falkland Current, a northward-flowing current between $55^{\circ} \mathrm{S}$ and $37^{\circ} \mathrm{S}$ that originates from the Antarctic Circumpolar Current (Peterson and Whitworth 1989, Acha et al. 2004). Upon reaching the continental slope to the south of the Falkland Islands, the Falkland Current splits into two main northward-flowing streams (east and west). To assess environmental change, we extracted Extended Reconstructed Sea Surface Temperature data (SST; ERSST.v3b) between 1854 and 2014 (the full extent of available data) from one area that captures the Falkland Current prior to its split, and two areas capturing the east and west northward flowing streams (Glorioso 2002). These regions were (1) south of the Falkland Islands $54-52^{\circ} \mathrm{S}$ and $60-58^{\circ} \mathrm{W}$, (2) west of the Falkland Islands $61-63^{\circ} \mathrm{W}$ and $51-53^{\circ} \mathrm{S}$, and (3) north of the Falkland Islands $57-59^{\circ} \mathrm{W}$ and $49-50^{\circ} \mathrm{S}$. Given otariid nutritional stress is typically greatest in winter and winter resource availability influences the success of pregnancy (Pitcher et al. 1998), we limited our analysis to an estimate of winter SST (calculated as the mean of June, July, and August).

To test the significance of SST changes over time, we ran a generalized additive model (GAM) for each region using the mgcv package (Wood 2011) in $\mathrm{R}(\mathrm{R}$ Core Team 2013). The GAM was implemented using year as a smooth term, cyclic cubic regression splines, and 20 knots. To determine whether the model required a correlation structure, we plotted the autocorrelation function (ACF) and partial ACF. This process revealed several large correlations in the residuals that approached the ACF cutoff of 0.2, but did not exceed it. Extending the GAM to a generalized additive mixed model (GAMM) with a correlation structure did not improve model fit (based on Akaike information criterion; AIC). Therefore, we analyzed SST using the GAM. Model validation was checked through plots of residuals and fitted values. To identify periods of significant SST change (periods along the fitted trend where the slope was significantly different from $0 ; P<0.05$ ), we computed the first derivatives of the fitted smoother using the method of
TABLE 4. The number of southern sea lion hides produced in Argentina between 1931 and 1960 (source: Godoy 1963).

\begin{tabular}{lc}
\hline \hline Year skins produced & Number of skins \\
\hline $1931-1935$ & 32911 \\
$1936-1940$ & 230339 \\
$1941-1945$ & 153971 \\
$1946-1950$ & 57351 \\
$1951-1955$ & 10728 \\
$1956-1960$ & 8138 \\
Total (1931-1960) & 493438 \\
\hline
\end{tabular}

Note: Data were drawn from the same report as the data presented in Table 3.

finite differences (Curtis and Simpson 2014). R code to reproduce the computation of finite differences is available online. ${ }^{10}$ All results are shown as mean \pm SD.

\section{RESUlts \\ Population census}

In total, 4443 pups were counted in 2014 at 70 breeding colonies that were distributed around $800 \mathrm{~km}$ of coastline (Fig. 2; Appendix A: Table A1). The number of pups counted increased by at least $60 \%$ when compared with the 2003 census (2765 pups, including dead pups). However, this is less than the 5506 SSL pups counted in 1965 and only $5 \%$ of the 1930s estimate (Appendix A: Table A1). The annual rate of increase between 2003 and 2014 was 8.5\%. One known breeding colony (Port Louis) was not counted but was estimated to have $64 \pm 105$ pups in 2014 (all means shown \pm SD; the lower and upper $95 \%$ confidence intervals were 22 and 127 pups, respectively). Including this breeding colony, the total number of pups estimated in 2014 is therefore between 4465 and 4570 .

\section{Hypotheses}

Decline was the result of commercial sealing at the Falkland Islands.-Commercial sealing was geographically isolated on the southern area of East and West Falkland (Fig. 1). In total, 60723 SSL were harvested in 13 years between 1928 and 1966 (Table 1). The main commercial sealing period was 1928-1939, when 56729 SSL were killed (Table 1). This estimate is $25 \%$ larger than the previous published estimate of 42741 SSL killed during the same period (Strange 1979). The majority (97\%) of SSL killed were males during the nonbreeding period (May-October; Fig. 3, Table 1). The only record of adult females and pups being killed was in 1930 during May $(n=360)$, June $(n=361)$, July $(n=$ $460)$, and October $(n=242$; Table 1$)$. We found inconsistencies in the number of SSL reported in telegrams, sealing reports, and letters. However, inconsistencies post-1935 (i.e., post-census) were $<1000 \mathrm{SSL}$,

${ }^{10} \mathrm{http}: / / w w w . f r o m t h e b o t t o m o f t h e h e a p . n e t / 2014 / 05 / 15 /$ identifying-periods-of-change-with-gams/ 


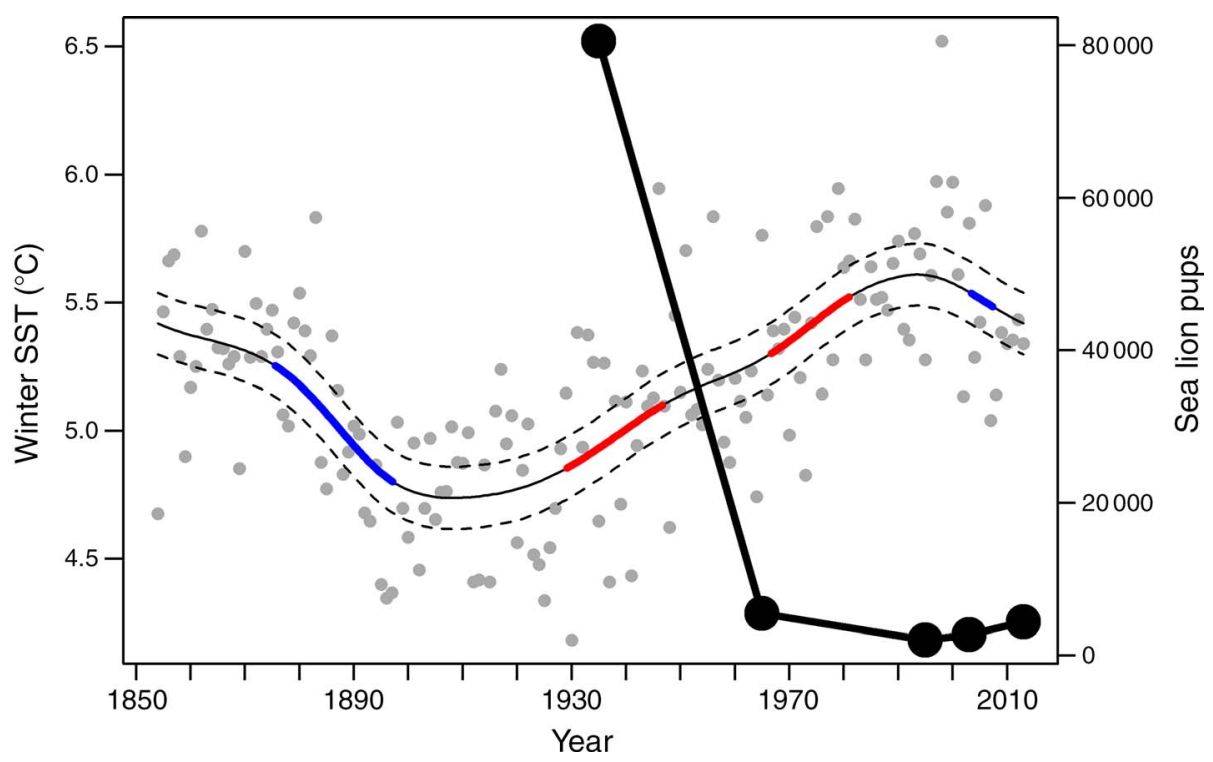

FIG. 2. Winter mean sea surface temperature (SST) data (gray dots; mean of June, July, and August) as a function of time at the Falkland Islands. The solid thin black line represents the fitted smoother (with $95 \%$ pointwise confidence intervals; dashed lines) of the generalized additive model (GAM). Finite differences were used to estimate the rate of change (slope) in the fitted GAM smoother and revealed two significant periods of SST decline (blue line, pre-1900s and post-2000) and two significant periods of SST increase (red line, 1930-1950 and 1965-1980). The solid thick black line shows the estimated number of southern sea lion pups at the Falkland Islands from the first census in the 1930s, and subsequent censuses in 1965, 1995, 2003, and 2014 (black circles).

implying the number of sea lions misreported was insignificant given the scale of the population decline (Table 1). Between 1935 and 1965, at least 32259 SSL were killed (Table 1). Over this period, the majority of SSL $(87 \%)$ were killed at three locations: Cape Meredith area (28\%), Arch Island group (24\%), and Sandbar Island (35\%; Fig. 1). These were primarily haul-out sites, with only 85 pups counted at Cape Meredith in the 1930s and 21 pups at the Arch Island group, while Sandbar Island was a nonbreeding site (see Appendix A: Table A1).
Census data based on pup counts reveal that SSL female pups declined by over $90 \%$, from 40277 pups in the 1930s (assuming a 50:50 sex ratio) to 2753 in 1965 . This is in contrast to our stationary population model, where, when we assumed sealing targeted only females, our model predicted that the number of female pups in 1965 would be 30213 (see Appendix B: Fig. B2). This is more than 10 times the actual number of pups in 1965 . Therefore, commercial sealing at the Falkland Islands could only account for an $11 \%$ decline in female SSL pups over the 32-yr study period, and cannot explain the

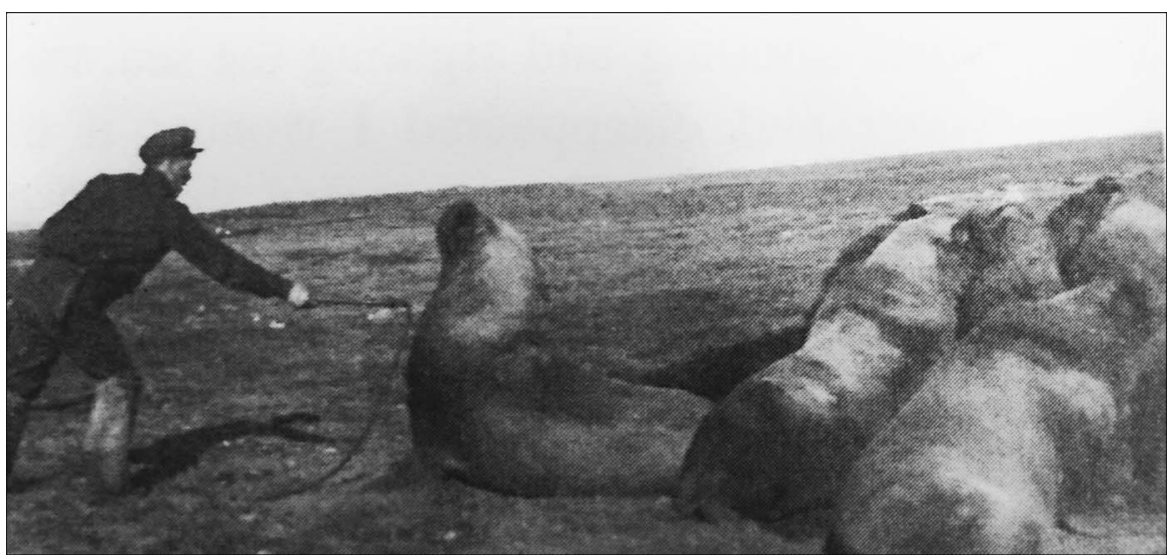

FIG. 3. Commercial sealing at the Falkland Islands predominantly targeted adult male southern sea lions, as shown in this 1930s photograph of southern sea lions being rounded up in West Falkland (source: Allen 2010). 


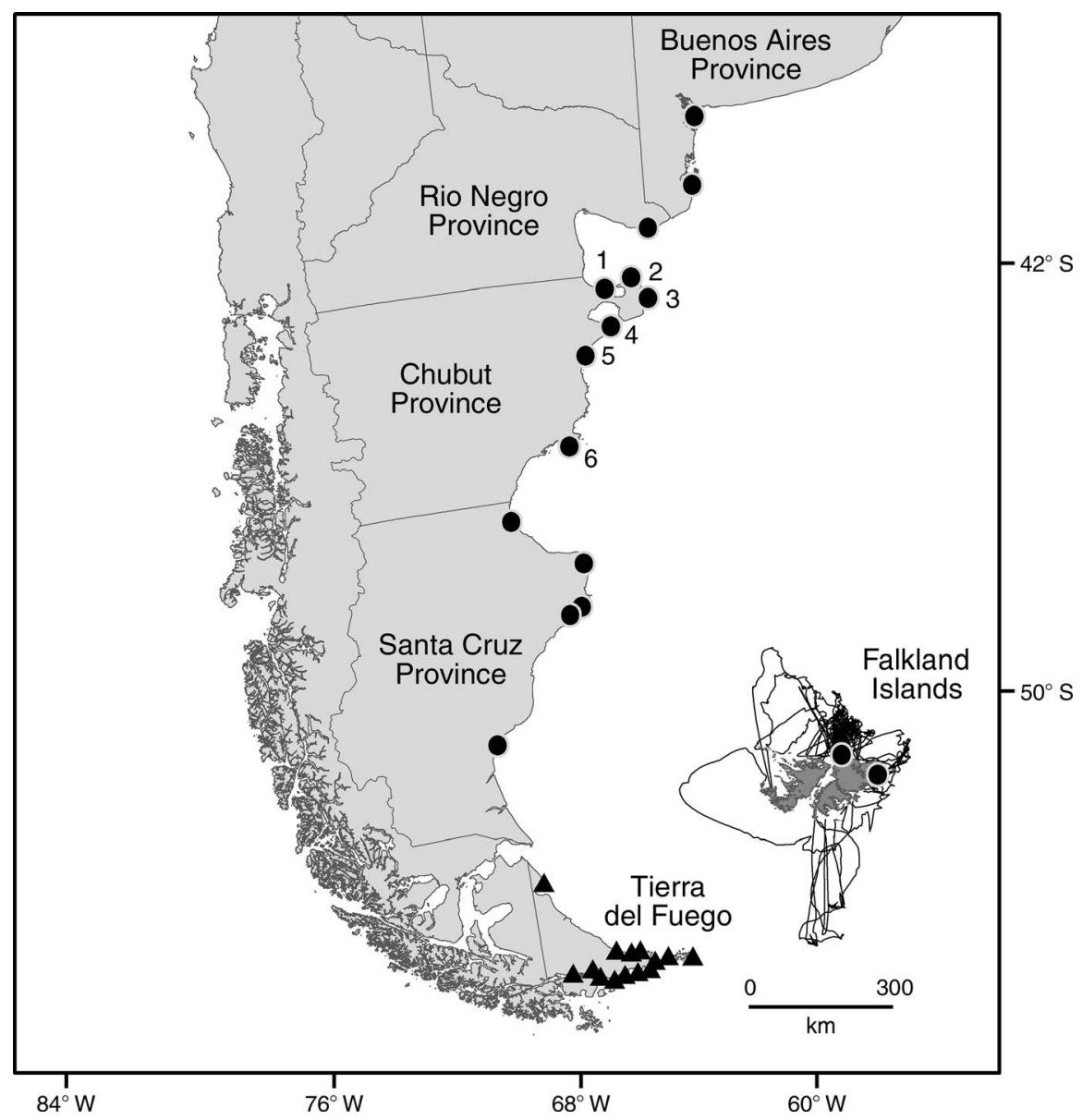

FIG. 4. Movements of eight juvenile southern sea lions tracked from the Falkland Islands during autumn and winter in 2011 and 2012. Deployment duration lasted between 24 and $206 \mathrm{~d}$. We did not detect a migration of southern sea lions to Argentina. Dots at the Falkland Islands represent the two deployment sites, Cape Dolphin (north) and Port Harriet (east). Also presented are select provinces in Argentina, with dots corresponding to the 14 sea lion colonies for which count data were available in 1938. No data were available for Tierra del Fuego in 1938; hence, triangles represent locations of colonies counted in 1950 (source: Godoy 1963). Colonies shown include Punta Buenos Aires (1), Punta Norte (2), Punta Delgada (3), Punta Ninfas (4), Isla Escondida (5), and Isla Rasa (6); see also Table 3.

scale of the population decline between the 1930s and 1965.

Commercial sealing in Argentina caused the decline in Falkland Islands due to winter migration of SSL from Falkland Islands to Argentina.-In total, six subadult males and four subadult females were equipped with PTT tags. Deployment duration ranged from 24 to $206 \mathrm{~d}$ (Table 2). A total of 12613 ARGOS locations were obtained. Our definition of a foraging trip ( $>5 \mathrm{~km}$ from land and $>2 \mathrm{~d}$ in duration) reduced the data set to only 5286 locations. Two PTT tags (numbers 68048 and 67957) were active for one month and though movements were recorded, none passed our foraging trip criteria (maximum distance from the Falkland Islands did not exceed $5 \mathrm{~km}$ ). For the remaining SSL tracked, the mean maximum foraging trip distance was $84 \pm 47$ $\mathrm{km}$ and mean duration was $4 \pm 1 \mathrm{~d}$ (Table 2). These results clearly show that, while extended movements were observed in some subadults, there was no evidence of a migration to Argentina or the South American mainland (Fig. 4).

SSL colonies in Argentina were unable to sustain the reported level of exploitation.-In 1938, a total of 671500 SSL were estimated in Argentina (excluding Tierra del Fuego; Godoy 1963; Table 3, Fig. 4). At least 493438 SSL were killed in Argentina, $78 \%$ of which were harvested between 1936 and 1945 (Table 4). From available census data, the number of SSL in Argentina declined by $78 \%$ between 1938 and 1950, to 144495 SSL (including 39900 counted in Tierra del Fuego; Table 3). Assuming a 50:50 sex ratio, this equals 72247 females in 1950. In comparison, our hypothetical SSL population was reduced to 67274 female SSL in 1950 (assuming male and female SSL were harvested equally; see Appendix B: Fig. B2), including 12208 female pups. Hence, it is feasible that our hypothetical Argentinean SSL population could have sustained the number of SSL killed in Argentina. 
Environmental change.-Over the entire time series, mean winter SST cooled by $0.6^{\circ} \mathrm{C}$ between $1854-1860$ and $1891-1900\left(5.3^{\circ} \pm 0.4^{\circ} \mathrm{C}\right.$ and $4.7^{\circ} \pm 0.2^{\circ} \mathrm{C}$, respectively). This was followed by a period of warming between 1921-1930 and 1991-2000, where the mean winter SST rose by $0.9^{\circ} \mathrm{C}$ from $4.8^{\circ} \pm 0.3^{\circ} \mathrm{C}$ (range $4.2-$ $5.1^{\circ} \mathrm{C}$ ) to $5.7^{\circ} \pm 0.4^{\circ} \mathrm{C}$ (range $5.3-6.5^{\circ} \mathrm{C}$; GAM: estimated $\mathrm{df}=5.7, F=8.5, P<0.001)$. Four periods of significant SST change were identified using the first derivative of the fitted smoother. These were a decline in the late $1800 \mathrm{~s}$, followed by a significant increase between 1930-1950 and 1965-1980, and a more recent SST decline (Fig. 2; see also Appendix C: Figs. C1 and C2). However, superimposed on these long-term changes were marked interannual differences in SST (Fig. 2). Overall, the GAM highlights an increase in SST that corresponds with the period of SSL decline.

\section{DisCusSION}

Understanding the drivers of long-term changes in species abundance remains one of the most significant questions in ecology, but is often hampered by the lack of long time series. While time series that document species abundance over one or two decades are relatively common, longer time series ( $>50$ years) are scant (Lotze and Worm 2009). In this context, the SSL data from the Falklands Islands are important because of the availability of census data from 80 years ago. These data reveal that, despite an increase in SSL over the past two decades, the number of pups born in 2014 is less than that reported in 1965 and only $6 \%$ of the 1930 s estimate. Accordingly, the time scale considered dramatically alters the interpretation of the recent increase in population size, echoing what has been termed the "shifting baseline syndrome" that is reported for a number of taxa around the world (e.g., Lotze and Worm 2009). When longer time scales are considered, the recent increase in SSL at the Falkland Islands is overshadowed by the precipitous decline between the 1930s and 1965.

The decline is unlikely to be an artifact of interannual variability in the proportion of SSL that attempt to breed from one year to the next. Although consecutive annual counts of SSL breeding at the Falkland Islands have not been undertaken, there is no evidence of large interannual variability in the number of pups born at other South Atlantic breeding sites, where more complete interannual census data exists (Dans et al. 2012). The decline is also unlikely to reflect fabricated counts in the 1930 s because only $3 \%$ of pups $(n=2675)$, or nine out of 64 sites surveyed, were estimated rather than direct counted (Hamilton 1939). Finally, although count methods varied between the 1930s census and later censuses (e.g., the 1965 aerial survey), error associated with different count methods is unlikely to be significant, given the magnitude of the decline.

To interpret the drivers of past changes in SSL abundance at the Falkland Islands, we critically reviewed the established paradigm and assessed alternative hypotheses. Due to inadequate data, we were unable to test (and, therefore, cannot exclude) at least three other factors that may have contributed to the SSL decline at the Falkland Islands. These were commercial fishing, disease, and predation (particularly by killer whales, given great whales were decimated in the Southern Hemisphere and top-down forcing is one factor that may have impeded SSL population recovery at the Falkland Islands between 1965 and 1995 [Branch and Williams 2006]). Although we discuss each of these potential factors (and the hypotheses tested) separately, we acknowledge any combination of factors may have acted in synergy.

Overfishing degrades the resilience of marine ecosystems to environmental perturbations and can alter the physical and trophic structure of ecosystems via habitat destruction and trophic disruption, respectively (Pauly et al. 1998, Myers and Worm 2003). At the Falkland Islands, commercial fishing commenced in the 1960s (for example, research cruises by Russia and Japan), but intensive near-shore trawl fisheries were not developed until the 1980s (Palmer 2004; Palomares and Pauly 2015). This is after the period of SSL decline. Other South Atlantic fisheries were in operation and a steady increase in catches was reported from the late 1950s onward (Drago et al. 2009, FAO 2011). However, South Atlantic resources remained underexploited or lightly exploited until the 1980s (FAO 2011). While we cannot exclude fisheries-induced changes to food webs, it seems unlikely fisheries removed ecologically significant quantities of prey between the 1930s and 1965 that would have impacted the SSL breeding at the Falkland Islands.

Disease outbreaks have caused mass mortalities in numerous pinniped species (Harwood and Hall 1990) and may have been a contributing factor in the Falkland Islands SSL population decline. Information on disease at the Falkland Islands is limited, but poxvirus, alopecia, and parasites such as hookworms (Uncinaria hamiltoni) occur (Hamilton 1939, Wilson and Poglayen-Neuwall 1971, Pistorius and Baylis 2010). Of these, hookworm enteritis can cause significant mortality in pinnipeds, and infestation may be density dependent (Spraker and Lander 2010). However, there is no evidence of epizootic mass mortality events at the Falkland Islands and carcasses from a zoonosis of similar severity to the distemper virus in the North Sea in the 1980s are unlikely to have gone unnoticed (Strange 1979, Harwood and Hall 1990).

Predation can have profound effects on the population trends of long-lived, slow-reproducing species that exhibit comparatively high and stable adult survival and low reproductive flexibility, such as pinnipeds (Estes et al. 1998, Schwarz et al. 2013). Leopard seals (Hydrurga leptonyx) and killer whales are potential SSL predators at the Falkland Islands. Leopard seals were targeted during commercial sealing operations, but very little is known about their abundance and distribution. The 
maximum number of leopard seals killed in a year was 28 (Dickinson 2007), implying leopard seals were once common at the Falkland Islands, albeit in low numbers. Killer whales are renowned for their attacks on elephant seals (Mirounga leonina) at the Falkland Islands and commonly prey on SSL at other breeding locations (most notably in Argentina; Hoelzel 1991, Yates et al. 2007). However, in the 1930s, killer whales were rarely reported at the Falkland Islands (Hamilton 1934) and more recent monthly at-sea surveys between February 1998 and January 2001 recorded killer whales on only seven occasions (a total of 18 killer whales; White et al. 2002). These observations do not necessarily indicate killer whales are rare or attacks on SSL are uncommon. Rather, the largest number of killer whales reported at any one time in the Falkland Islands is 12, which compares favorably to the size of pods that prey on SSL at breeding colonies in Argentina (Hoelzel 1991, Yates et al. 2007). Hence, based on the apparent low numbers of leopard seals and killer whales around the Falkland Islands, and considering the energetic demands of these species outlined in Branch and Williams (2006) and Schwarz et al. (2013), it is improbable predation was the primary cause of the Falkland Islands SSL population decline.

\section{Hypotheses}

Commercial sealing at the Falkland Islands.-We found that the number of SSL killed during commercial sealing operations at the Falkland Islands was higher than previously estimated (Strange 1979). However, commercial sealing was geographically restricted and principally targeted adult male SSL. If commercial sealing records are accurate, then sealing had little effect on the age structure of the female (reproductively important) component of the population. The removal of a large number of males may still have impacted the population, but the effect would be complex and unlikely to be a driver in the rapid decline of a polygynous species. Even when we assumed commercial sealing had targeted only female SSL, our population model predicted a decline of only $11 \%$ based on our revised (higher) sealing estimates (comparable to the $6 \%$ previously reported; Thompson et al. 2005). Consequently, commercial sealing at the Falkland Islands cannot account for the magnitude of the decline (even if large discrepancies exist between the number and sex of SSL killed and the number reported).

In the 1920s, landowners also killed an unknown quantity of SSL of all age classes to preserve tussac grass (Poa flabellata); a valuable feed for livestock (Hamilton 1939). However, this was prior to the 1930s census. While the preservation of tussac grass was common practice in the 1920s, we were unable to find evidence that casual killing was common practice during the period of decline (1930s to 1965). Unreported casual killing may explain declines at select breeding colonies. However, many of the large SSL breeding colonies in the 1930s were on remote islands (Hamilton 1939). This would have necessitated a coordinated, systematic, and large-scale cull that was contrary to the interests of the commercial sealing industry at the Falkland Islands. In addition, illegal sealing may have existed, but it is unlikely to have occurred on the scale required to cause the decline without being noticed (Strange 1979, Dickinson 2007). Therefore, it is improbable that local culls or illegal sealing can account for the population decline.

Commercial sealing in Argentina caused the decline in Falkland Islands due to winter migration of SSL from Falkland Islands to Argentina.-The Falkland Islands are only $500 \mathrm{~km}$ from the coastline of Argentina and, therefore, within the range of at least one SSL tracked during our study (Fig. 4). Hence, we expect some level of individual exchange between Argentina and the Falkland Islands (Feijoo et al. 2011, Giardino et al. 2014). However, we did not detect a winter migration of subadult SSL to mainland South America.

We acknowledge caveats exist with our approach of deploying PTT tags to explore migration. Firstly, recent studies highlight marked seasonal movements of adult male SSL in Argentina (Giardino et al. 2014). Given not all age classes were tracked, we cannot exclude agespecific (differential) migration. Secondly, marine ecosystems around the Falkland Islands have been radically altered in recent decades by intensive commercial fishing (Laptikhovsky et al. 2013). Hence, SSL winter movements in 2011 and 2012 may not be representative of SSL winter movements in the 1930s. Thirdly, the large Falkland Islands SSL population in the 1930s could have depleted resources around breeding colonies during the breeding season and a winter migration to other productive areas may have been necessary (i.e., Ashmole 1963). Finally, sealing could have altered the evolution of heritable traits because SSL predisposed to migration were killed (e.g., Barbraud et al. 2013).

Nonetheless, commercial sealing data does not support the notion of a winter migration. Specifically, commercial sealing at the Falkland Islands operated during winter months, implying some proportion of adult male SSL did not migrate during the years of commercial sealing. Sealing operations typically ceased by October because the availability of male SSL at (predominantly) nonbreeding sites declined. While we cannot discount a migration in October, a more compelling argument is that male SSL were preparing for the breeding season and beginning to disperse to breeding colonies (Hamilton 1934). In addition, sealing records also revealed adult females and pups were killed between May and August 1930, implying at least some proportion of adult females did not migrate during winter. This is unsurprising given adult female SSL are obligate central place foragers over winter, and philopatry to haul-out sites is reported at some South Atlantic SSL colonies (Rodríguez et al. 2013). At the Falkland Islands, adult female SSL do disperse away from breeding colonies and alter their haul-out locations 
over winter, as is reported for other sea lion species (Hamilton 1939, Thompson et al. 1998, Raum-Suryan et al. 2004). This presumably is a response to adult male aggression or changes in the availability and distribution of preferred prey (Womble et al. 2009). Although it is not unusual for individuals to travel extended distances (hundreds of kilometres) when pups are 6 months old (e.g., Raum-Suryan et al. 2004), sea lions are generally considered to be nonmigratory. A winter migration of adult female SSL from the Falkland Islands is therefore at odds with what is currently known about sea lion life histories.

SSL colonies in Argentina were unable to sustain the reported level of exploitation.-Census and sealing data from Argentina between 1930 and 1960 (Godoy 1963) challenges the notion that SSL colonies in Argentina were unable to sustain the reported level of exploitation, thereby necessitating a migration from the Falkland Islands to account for the number of SSL killed (Thompson et al. 2005, Branch and Williams 2006). In 1938, the number of SSL estimated in Argentina (excluding Tierra del Fuego) was almost twice as large as the Falkland Islands population ( $\sim 671500$; Godoy 1963). This estimate was overlooked in previous studies. For example, Branch and Williams (2006) derive 349000 SSL in 1938 based primarily on post-1945 count data, underestimating the number of SSL in Argentina by $48 \%$ (thus supporting the notion that SSL in Argentina were unable to support the reported level of exploitation). We tested whether a hypothetical Argentinean SSL population (based on a population of 671500 SSL that included 58532 female pups), could have sustained the reported 460527 SSL killed between 1936 and 1960. While overly simplified due to the paucity of available data, our stationary population model proved that it was indeed feasible. Hence, there is no inherent reason to assume a winter migration from the Falkland Islands was necessary to account for the number of SSL killed in Argentina.

Indeed, the combined Falkland Islands and Argentinean SSL population was likely to have been $>1$ million in the 1930s (rather than the previously reported 729000 SSL), and the combined decline between the 1930s and 1965 closer to 868500 SSL (rather than the previously reported $461000 \mathrm{SSL}$; Branch and Williams 2006). The decline is $36 \%$ greater than the combined total estimate of 554161 SSL killed during commercial sealing operations in Argentina (493438 SSL; 19311960) and the Falkland Islands (60723 SSL; 19281966). Therefore, we argue that although commercial sealing drastically reduced the SSL population in Argentina, it does not account for the Falkland Islands decline.

A second seminal study merged counts at the Falkland Islands with select SSL colonies in the Chubut Province of Argentina to explain the decline at the Falkland Islands (four of six colonies, where a discrepancy exists between the number killed and colony size; see Fig. 4, Table 3; Thompson et al. 2005). Chubut Province is 1000 $\mathrm{km}$ from the Falkland Islands. Accordingly, we argue discrepancies in the number of SSL killed at select colonies in the Chubut Province may more immediately be resolved by immigration or seasonal movements from adjacent colonies in Argentina and Uruguay (Giardino et al. 2014), rather than a winter migration of SSL from the Falkland Islands to Argentina.

Environmental change.-Some ecosystems have available data sets that enable drivers of population change to be tested. Examples include the North Atlantic, where long-term changes in the abundance of marine plankton are linked to changes in SST, and some terrestrial vertebrate systems where climate, predation, and density-dependent factors can be partitioned (Coulson et al. 2001, Hays et al. 2005). Unfortunately, much of the data required to understand potentially complex genetic, phenotypic, life-history, and demographic responses to environmental change (Coulson et al. 2011) are not available for SSL at the Falkland Islands. It is well documented that rapid, persistent environmental changes have occurred in adjacent Pacific and Southern Ocean marine ecosystems. For example, there is compelling evidence (air and ocean temperatures, atmospheric carbon dioxide, and landings of anchovies and sardines) of a regime shift in the Pacific Ocean during the mid1900s (Chavez et al. 2003). Similarly, in the Southern Ocean, declines in some penguin and pinniped species between the 1970s and 1990s correspond with changes in SST, weather, and sea-ice patterns (Croxall et al. 2002, Weimerskirch et al. 2003, Ainley et al. 2005, Jenouvrier et al. 2005), and changes in the balance of top-down and bottom-up control due to commercial fishing and industrial whaling (Pauly et al. 1998, Myers and Worm 2003, Branch and Williams 2006, Ainley et al. 2007, Ainley and Blight 2009). It is also known that changes in SST (and the underlying physical processes) can be manifested as large changes in marine predator abundance over short temporal scales (Forcada et al. 2005, Irons et al. 2008). For example, the 1997-1998 El Niño resulted in an $81 \%$ decline in the number of SSL in Peru (from 144087 SSL in 1997 to 27991 in 1999; Soto et al. 2004, Dans et al. 2012).

Our analysis revealed an increase in average winter SST around the Falkland Islands from the early 1900s onward, with a marked increase occurring between 1930 and 1950. SST changes of around $1^{\circ} \mathrm{C}$, i.e., the magnitude of long-term changes we report, can precipitate major changes in plankton communities, drive shifts in species abundance and phenology, and may lead to bottom-up forcing on higher trophic levels (e.g., Montevecchi and Myers 1997). This process of bottomup forcing has, for example, driven long-term changes in the abundance of some commercially exploited fish species (Hays et al. 2005). It is, therefore, reasonable to expect persistent SST changes around the Falkland Islands to influence habitat quality and biological patterns and processes (e.g., the spawning dynamics and recruitment of fish and squid), that may have altered 
the quantity, quality, or accessibility of preferred SSL prey during the period of decline (Waluda et al. 1999, Arkhipkin et al. 2010). However, we also found marked interannual variations in winter SST that presumably could have also impacted SSL population dynamics. Hence, a better temporal resolution of population data is ultimately required to understand potential links between population changes and gradual shifts in mean environmental conditions versus changes in the frequency of extreme environmental events.

If long-term changes in SST disrupted food webs and altered prey availability, SSL could have responded by shifting their range (e.g., emigrate from the Falkland Islands). For example, an increase in the number of SSL in Chile after the 1997-1998 El Niño is thought to reflect immigration from Peru (Dans et al. 2012). Depending on their degree of dietary specialization, SSL could have also responded by changing their diet. While dietary information pertaining to SSL at the Falkland Islands is limited, SSL dietary changes (inferred from changes in $\delta^{13} \mathrm{C}$ and $\delta^{15} \mathrm{~N}$ values) were detected between the $1940 \mathrm{~s}$ and 1970s in Patagonia (Drago et al. 2009). Although these results are consistent with the period of SST change we report, it is unclear when the dietary changes occurred and whether they relate to changes in density dependence due to commercial sealing, the development of intensive commercial fisheries, or climate changes (Drago et al. 2009).

Alternatively, populations may decline if they are unable to adapt to rapid shifts in environmental conditions (via reduced fecundity and survivorship; Irons et al. 2008). This hypothesis is compelling because SSL are typically considered to be benthic foragers (Thompson et al. 1998). This energetically costly foraging mode is characterized by animals using more of their physiological capacity when compared to other foraging modes (i.e., epipelagic or mesopelagic; Gallagher et al. 2014). Hence, SSL may have less capability to increase foraging effort in response to a persistent change in prey availability (Costa et al. 2004, Costa 2008). Additionally, if SSL specialize on demersal prey, as in other benthic-foraging sea lion species, they could be disproportionately vulnerable if resources become suddenly depleted, when compared to a population of generalists (Gallagher et al. 2014). While more work is needed to understand SSL foraging ecology at the Falkland Islands, our hypothesis that physical forcing (the result of a persistent increase in SST) altered the availability of SSL prey in the mid-1900s provides a framework to better explain the SSL decline, and may provide new insights into why SSL have failed to recover in the 50 years since the cessation of sealing.

Nevertheless, coincidence is not causality. We cannot resolve whether the SSL decline may have reflected a simple linear chain of species-level responses to SST change, or involved more complex feedback cycles and nonlinear responses to environmental variability (e.g., Croxall 1992, Forcada et al. 2008). Nor can we tease apart how the main factors discussed may have acted in synergy, although more complete and extended time series for pinnipeds at other sites do offer some potential in resolving similar synergistic effects (e.g., Forcada et al. 2005). However, we can establish that environmental change is the most parsimonious of the hypotheses tested. Our study not only reshapes our understanding of the factors that may have caused the SSL decline, but, in recognizing that pervasive changes in ocean climate may have already influenced SSL abundance, it also has implications for how we interpret threats to SSL persistence and the efficiency of contemporary conservation measures. Set against a backdrop of few very long ( $>50$ year) time series of species abundance for marine vertebrates, our work highlights the value of piecing together a picture of long-term changes from fragmented data, notably with regard to the shifting baselines syndrome for once heavily exploited species. In particular we suggest that historical harvesting, which is often viewed as the most likely cause of long-term declines, may not always be the "smoking gun." Instead, environmental changes in the mid-1900s could have also profoundly impacted higher trophic levels across a broad range of ecosystems.

\section{ACKNOWLEDGMENTS}

For facilitating research, we thank Rincon Grande farm, Elephant Beach farm, Cape Dolphin farm, A. Blake, P. Brickle, R. Cordiero, C. Dockrill, J. Fenton, T. Newman, and N. Rendell. $\mathrm{We}$ are indebted to $\mathrm{L}$. Poncet for sailing us around the Falklands. A. M. M. Baylis gratefully acknowledges T. Branch and D. Thompson for sharing their data, the Elephant Seal Research Group for counting Sea Lion Island, A. Schimel, and two anonymous reviewers who improved earlier manuscript drafts. A. M. M. Baylis and I. J. Staniland received funding from the Darwin Initiative and Project AWARE for PTT deployments. A. M. M. Baylis received funding from the Shackleton Scholarship Fund (Centenary Award), Rufford Small Grants, Sea World and Busch Gardens Conservation Fund, Joint Nature Conservation Council, and the Falkland Islands Government for the 2014 census. A. M. M. Baylis also gratfully acknowledges funding received from National Geographic and the Winnifred Violet Scott Charitable Trust. A. M. M. Baylis conceived the study. A. M. M. Baylis and R. A. Orben completed the fieldwork. A. M. M. Baylis, F. Christiansen, G. C. Hays, and I. J. Staniland analyzed the data. A. M. M. Baylis wrote the paper with G. C. Hays and contributions from all authors. Research was conducted under permits R14/2011 and R14/2013 issued by the Falkland Islands Government.

\section{Literature Cited}

Acha, E. M., H. W. Mianzan, R. A. Guerrero, M. Favero, and J. Bava. 2004. Marine fronts at the continental shelves of austral South America. Journal of Marine Systems 44:83105.

Ainley, D. G., et al. 2007. Paradigm lost, or is top-down forcing no longer significant in the Antarctic marine ecosystem? Antarctic Science 19:283-290.

Ainley, D. G., and L. K. Blight. 2009. Ecological repercussions of historical fish extraction from the Southern Ocean. Fish and Fisheries 10:13-38.

Ainley, D. G., E. D. Clarke, K. Arrigo, W. R. Fraser, A. Kato, K. J. Barton, and P. R. Wilson. 2005. Decadal-scale changes in the climate and biota of the Pacific sector of the Southern Ocean, 1950s to the 1990s. Antarctic Science 17:171-182.

Ainley, D. G., and K. H. Hyrenbach. 2010. Top-down and bottom-up factors affecting seabird population trends in the California current system (1985-2006). Progress in Oceanography 84:242-254.

Allen, J. R. 2010. Sealing on the Falkland Islands. Haydon Rowe, Southampton, UK. 
Anderson, P. J., and J. F. Piatt. 1999. Community reorganization in the Gulf of Alaska following ocean climate regime shift. Marine Ecology Progress Series 189:117-123.

Arkhipkin, A. I., P. Brickle, and V. Laptikhovsky. 2010. The use of island water dynamics by spawning red cod, Salilota australis (Pisces: Moridae) on the Patagonian Shelf (Southwest Atlantic). Fisheries Research 105:156-162.

Ashmole, N. P. 1963. The regulation of numbers of tropical oceanic birds. Ibis 103b:458-473.

Barbraud, C., G. N. Tuck, R. Thomson, K. Delord, and H. Weimerskirch. 2013. Fisheries bycatch as an inadvertent human-induced evolutionary mechanism. PLoS ONE 8: e60353.

Barnosky, A. D., et al. 2011. Has the Earth's sixth mass extinction already arrived? Nature 471:51-57.

Baylis, A. M. M., B. Page, I. Staniland, J. Arnould, and J. McKenzie. 2015. Taking the sting out of darting: risks, restraint drugs and procedures for the chemical restraint of Southern Hemisphere otariids. Marine Mammal Science 31: 322-344.

Branch, T., and T. M. Williams. 2006. Legacy of industrial whaling: could killer whales be responsible for declines in Southern Hemisphere sea lions, elephant seals and minke whales? Pages 262-278 in J. A. Estes, D. P. DeMaster, R. L. Brownell, D. F. Doak, and T. Williams, editors. Whales, whaling and ocean ecosystems. University of California Press, Berkeley, California, USA.

Campagna, C. 2014. Otaria bryonia. The IUCN red list of threatened species. Version 2014.3. www.iucnredlist.org

Caughley, G., and A. Gunn. 1996. Conservation biology in theory and practice. Blackwell, Cambridge, Massachusetts, USA.

Chavez, F. P., J. Ryan, S. E. Lluch-Cota, and M. Ñiquen C. 2003. From anchovies to sardines and back: multidecadal change in the Pacific Ocean. Science 299:217-221.

Costa, D. P. 2008. A conceptual model of the variation in parental attendance in response to environmental fluctuation: foraging energetics of lactating sea lions and fur seals. Aquatic Conservation: Marine and Freshwater Ecosystems 17:S44-S52.

Costa, D. P., C. E. Kuhn, M. J. Weise, S. A. Shaffer, and J. P. Y. Arnould. 2004. When does physiology limit the foraging behaviour of freely diving mammals? International Congress Series 1275:359-366.

Coulson, T., E. A. Catchpole, S. D. Albon, B. J. Morgan, J. M. Pemberton, T. H. Clutton-Brock, M. J. Crawley, and B. T. Grenfell. 2001. Age, sex, density, winter weather, and population crashes in Soay sheep. Science 292:1528-1531.

Coulson, T., D. R. MacNulty, D. R. Stahler, B. VonHoldt, R. K. Wayne, and D. W. Smith. 2011. Modeling effects of environmental change on wolf population dynamics, trait evolution, and life history. Science 334:1275-1278.

Crespo, E. A., and S. Padraza. 1991. Estado actual y tendencia de la población de lobos marinos de un pelo (Otaria favescens) en el litoral norpatagónico. Ecologia Austral 8795. [In Spanish.]

Croxall, J. P. 1992. Southern Ocean environmental changes: effects on seabird, seal and whale populations. Philosophical Transactions of the Royal Society B 338:319-328.

Croxall, J. P., P. N. Trathan, and E. J. Murphy. 2002. Environmental change and Antarctic seabird populations. Science 297:1510-1514.

Curtis, C. J., and G. L. Simpson. 2014. Trends in bulk deposition of acidity in the UK, 1988-2007, assessed using additive models. Ecological Indicators 37:274-286.

Dans, S., W. Sielfeld, A. Aguayo, G. Giardino, and M. A. Mandiola. 2012. Status and tendencies of the populations. Pages 1-146 in E. Crespo, D. Oliva, S. Dans, and M. Sepulveda, editors. Current status of the South American sea lion along the distribution range. Universidad de Valparaíso Editoria, Valparaíso, Chile.
Dickinson, A. B. 2007. Seal fisheries of the Falkland Islands and dependencies: an historical review. St. John's, Newfoundland, International Maritime Economic History Association.

Dirzo, R., H. S. Young, M. Galetti, G. Ceballos, N. J. B. Isaac, and B. Collen. 2014. Defaunation in the Anthropocene. Science 345:401-406.

Drago, M., E. Crespo, A. Aguilar, L. Cardona, N. García, S. Dans, and N. Goodall. 2009. Historic diet change of the South American sea lion in Patagonia as revealed by isotopic analysis. Marine Ecology Progress Series 384:273-286.

Estes, J. A., D. F. Doak, A. M. Springer, and T. M. Williams. 2009. Causes and consequences of marine mammal population declines in southwest Alaska: a food-web perspective. Philosophical Transactions of the Royal Society B 364:1647-1658.

Estes, J. A., M. T. Tinker, T. M. Williams, and D. F. Doak. 1998. Killer whale predation on sea otters linking oceanic and nearshore ecosystems. Science 282:473-476.

FAO. 2011. Review of the state of world marine fishery resources. Technical paper no. 569. Food and Agriculture Organization of the United Nations, Rome, Italy.

Feijoo, M., E. P. Lessa, R. Loizaga de Castro, and E. A. Crespo. 2011. Mitochondrial and microsatellite assessment of population structure of South American sea lion (Otaria flavescens) in the Southwestern Atlantic Ocean. Marine Biology 158:1857-1867.

Forcada, J., P. N. Trathan, and E. J. Murphy. 2008. Life history buffering in Antarctic mammals and birds against changing patterns of climate and environmental variation. Global Change Biology 14:2473-2488.

Forcada, J., P. N. Trathan, K. Reid, and E. J. Murphy. 2005. The effects of global climate variability in pup production of Antarctic fur seals. Ecology 86:2408-2417.

Gallagher, A. J., N. Hammerschlag, S. J. Cooke, D. P. Costa, and D. J. Irschick. 2014. Evolutionary theory as a tool for predicting extinction risk. Trends in Ecology \& Evolution 30: 61-65.

Gerber, L. R., and R. Hilborn. 2001. Catastrophic events and recovery from low densities in populations of otariids: implications for risk of extinction. Mammal Review 31: $131-150$.

Giardino, G. V., M. A. Mandiola, J. Bastida, P. E. Denuncio, R. O. Bastida, and D. H. Rodríguez. 2015. Travel for sex: long-range breeding dispersal and winter haulout fidelity in southern sea lion males. Mammalian Biology. http://dx.doi. org/10.1016/j.mambio.2014.12.003

Glorioso, P. D. 2002. Modelling the South West Atlantic. Aquatic Conservation: Marine and Freshwater Ecosystems 12:27-37.

Godoy, J. 1963. Fauna Argentina. Consejo Federal de Inversiones. Serie Evaluacibn de 10s Recursos Naturales Renovables Buenos Aires, Argentina. [In Spanish.]

Hamilton, J. E. 1934. The southern sea lion, Otaria byronia (de Blainville). Discovery Reports 8:269-318.

Hamilton, J. E. 1939. A second report on the southern sea lion, Otaria byronia (de Blainville). Discovery Reports 19:121-164.

Hare, S. R., and N. J. Mantua. 2000. Empirical evidence for North Pacific regime shifts in 1977 and 1989. Progress in Oceanography 47:103-145.

Harwood, J., and A. Hall. 1990. Mass mortality in marine mammals: its implications for population dynamics and genetics. Trends in Ecology \& Evolution 5:254-257.

Hays, G. C., A. J. Richardson, and C. Robinson. 2005. Climate change and marine plankton. Trends in Ecology \& Evolution 20:337-344.

Hoelzel, A. R. 1991. Killer whale predation on marine mammals at Punta Norte, Argentina; food sharing, provisioning and foraging strategy. Behavioral Ecology and Sociobiology 29:197-204.

Hückstädt, L. A., R. A. Quiñones, M. Sepúlveda, and D. P. Costa. 2014. Movement and diving patterns of juvenile male South American sea lions off the coast of central Chile. Marine Mammal Science 30:1175-1183. 
Irons, D. B., et al. 2008. Fluctuations in circumpolar seabird populations linked to climate oscillations. Global Change Biology 14:1455-1463.

Jenouvrier, S., H. Weimerskirch, C. Barbraud, B. Cazelles, and Y. Park. 2005. Evidence of a shift in the cyclicity of Antarctic seabird dynamics linked to climate. Proceedings of the Royal Society B 272:887-895.

Johnson, D., J. London, M. Lea, and J. Durban. 2008. Continuous-time correlated random walk model for animal telemetry data. Ecology 89:1208-1215.

Laptikhovsky, V., A. Arkhipkin, and P. Brickle. 2013. From small bycatch to main commercial species: explosion of stocks of rock cod Patagonotothen ramsayi (Regan) in the Southwest Atlantic. Fisheries Research 147:399-403.

Lotze, H. K., and B. Worm. 2009. Historical baselines for large marine animals. Trends in Ecology \& Evolution 24:254-262.

Montevecchi, W. A., and R. A. Myers. 1997. Centurial and decadal oceanographic influences on changes in northern gannet populations and diets in the north-west Atlantic: implications for climate change. ICES Journal of Marine Science 54:608-614.

Myers, R. A., and B. Worm. 2003. Rapid worldwide depletion of predatory fish communities. Nature 423:280-283.

Palmer, S. 2004. Far from moderate. Dissertation. University of Portsmouth, Portsmouth, UK.

Palomares, M. L. D., and D. Pauly. 2015. Fisheries of the Falkland Islands and the British Antarctic Islands. Pages 120 in M. L. D Palomares and D. Pauly, editors. Marine Fisheries Catches of SubAntarctic Islands, 1950-2010. Fisheries Centre Research Reports 23(1). Fisheries Centre, University of British Columbia, Vancouver, British Columbia, Canada.

Pauly, D., V. Christensen, J. Dalsgaard, R. Froese, and F. J. Torres. 1998. Fishing down marine food webs. Science 279: $860-863$.

Peterson, R. G., and T. Whitworth III. 1989. The subantarctic and polar fronts in relation to deep water masses through the southwestern Atlantic. Journal of Geophysical Research 94: 10817-10838.

Pistorius, P. A., and A. M. M. Baylis. 2010. A bald encounter: hairless southern sea lion at the Falkland Islands. Polar Biology 34:145-147.

Pitcher, K., D. Calkins, and G. Pendleton. 1998. Reproductive performance of female Steller sea lions: an energetics-based reproductive strategy? Canadian Journal of Zoology 76: 2075-2083.

R Core Team. 2013. R: a language and environment for statistical computing. R Foundation for Statistical Computing, Vienna, Austria. www.r-project.org

Raum-Suryan, K., M. Rehberg, G. Pendleton, K. Pitcher, and T. Gelatt. 2004. Development of dispersal, movement patterns, and haul-out use by pup and juvenile Steller sea lions (Eumetopias jubatus) in Alaska. Marine Mammal Science 20:823-850.

Riet-Sapriza, F. G., D. P. Costa, V. Franco-Trecu, Y. Marín, J. Chocca, B. González, G. Beathyate, B. Louise Chilvers, and L. A. Hückstadt. 2013. Foraging behavior of lactating South American sea lions (Otaria flavescens) and spatial-temporal resource overlap with the Uruguayan fisheries. Deep Sea Research Part II: Topical Studies in Oceanography 88-89: 106-119.

Rodríguez, D. H., M. Dassis, A. Ponce de León, C. Barreiro, M. Farenga, R. O. Bastida, and R. W. Davis. 2013. Foraging strategies of southern sea lion females in the La Plata River Estuary (Argentina-Uruguay). Deep Sea Research Part II: Topical Studies in Oceanography 88-89:120-130.
Schwarz, L. K., M. E. Goebel, D. P. Costa, and A. M. Kilpatrick. 2013. Top-down and bottom-up influences on demographic rates of Antarctic fur seals Arctocephalus gazella. Journal of Animal Ecology 82:903-911.

Soto, K. H., A. W. Trites, and M. Arias-Schreiber. 2004. The effects of prey availability on pup mortality and the timing of birth of South American sea lions (Otaria flavescens) in Peru. Journal of Zoology 264:419-428.

Spraker, T. R., and M. E. Lander. 2010. Causes of mortality in northern fur seals (Callorhinus ursinus), St. Paul Island, Pribilof Islands, Alaska, 1986-2006. Journal of Wildlife Diseases 46:450-473.

Springer, A. M., J. A. Estes, G. B. van Vliet, T. M. Williams, D. F. Doak, E. M. Danner, K. A. Forney, and B. Pfister. 2003. Sequential megafaunal collapse in the North Pacific Ocean: an ongoing legacy of industrial whaling? Proceedings of the National Academy of Sciences USA 100:12223-12228.

Strange, I. 1979. Sealion survey in the Falklands. Oryx 15:175184.

Stubben, C. J. and B. G. Milligan. 2007. Estimating and analyzing demographic models using the popbio package in R. Journal of Statistical Software 22:11.

Thompson, D., C. D. Duck, B. J. McConnell, and J. Garrett. 1998. Foraging behaviour and diet of lactating female southern sea lions (Otaria flavescens) in the Falkland Islands. Journal of Zoology 246:135-146.

Thompson, D., I. Strange, M. Riddy, and C. Duck. 2005. The size and status of the population of southern sea lions Otaria flavescens in the Falkland Islands. Biological Conservation 121:357-367.

Trites, A. W., and P. A. Larkin. 1996. Changes in the abundance of Steller sea lions (Eumetopias jubatus) in Alaska from 1956 to 1992: how many were there? Aquatic Mammals 22.3:153-166.

Trites, A. W., et al. 2007. Bottom-up forcing and the decline of Steller sea lions (Eumetopias jubatus) in Alaska: assessing the ocean climate hypothesis. Fisheries Oceanography 16:46-67.

Waluda, C., P. Trathan, and P. Rodhouse. 1999. Influence of oceanographic variability on recruitment in the Illex argentinus (Cephalopoda: Ommastrephidae) fishery in the South Atlantic. Marine Ecology Progress Series 183:159-167.

Weimerskirch, H., P. Inchausti, C. Guinet, and C. Barbraud. 2003. Trends in bird and seal populations as indicators of a system shift in the Southern Ocean. Antarctic Science 15: 249-256.

White, R. W., K. W. Gillon, A. D. Black, and J. B. Ried. 2002. The distribution of seabirds and marine mammals in Falkland Islands waters. Joint Nature Conservation Commission, Peterborough, UK.

Wilson, T. M., and I. Poglayen-Neuwall. 1971. Pox in South American sea lions (Otaria byronia). Canadian Journal of Comparative Medicine 35:174-177.

Womble, J. N., M. F. Sigler, and M. F. Willson. 2009. Linking seasonal distribution patterns with prey availability in a central-place forager, the Steller sea lion. Journal of Biogeography 36:439-451.

Wood, S. N. 2011. Fast stable restricted maximum likelihood and marginal likelihood estimation of semiparametric generalized linear models. Journal of the Royal Statistical Society B 73(1):3-36.

Yates, O., A. D. Black, and P. Palavecino. 2007. Site fidelity and behaviour of killer whales (Orcinus orca) at Sea Lion Island in the Southwest Atlantic. Latin American Journal of Aquatic Mammals 6:89-95.

York, A. E. 1994. The population dynamics of northern sea lions, 1975-1985. Marine Mammal Science 10:38-51.

Supplemental Material

\section{Ecological Archives}

Appendices A-C are available online: http://dx.doi.org/10.1890/14-1948.1.sm 